\title{
The Fundamental Movement Skills of a Year 9 Group and a Gifted and Talented Cohort
}

\author{
Gillian Griffiths, Rebecca Billard \\ Department of Sport and Physical Activity, Edge Hill University, Ormskirk, UK \\ Email: Gillian.Griffiths@edgehill.ac.uk
}

Received August $1^{\text {st }}$, 2013; revised September $1^{\text {st }}$, 2013; accepted September $8^{\text {th }}$, 2013

\begin{abstract}
Copyright ( 2013 Gillian Griffiths, Rebecca Billard. This is an open access article distributed under the Creative Commons Attribution License, which permits unrestricted use, distribution, and reproduction in any medium, provided the original work is properly cited.
\end{abstract}

\begin{abstract}
Physical Education is often viewed as the place where Fundamental Motor Skills (FMS) are developed. These skills underpin the development of motor competence and perceived competence, therefore impacting on participation and physical literacy. Within education, Gifted and Talented (G \& T) and inclusion agendas have been high profile yet research has shown that children across the world are not reaching expected levels of skill mastery at primary level ( 5 - 11 years). The aim of the research was therefore to investigate the levels of mastery at secondary level (11 - 16 years) and within a G \& T cohort to establish their levels of mastery, and investigate how this may relate to their participation in physical activities. Forty five children, 19 Year 9 pupils (13.24 \pm 0.2 years) and $26 \mathrm{G} \& \mathrm{~T}$ pupils (13.24 \pm 0.2 years) were evaluated performing a combination locomotor, manipulative (object control) and balance skills $(n=5) .5$ trials of each skill were recorded and graded against the performance criteria by one experimenter. Mastery or near mastery were only achieved, if, in 4 out of the 5 trials, 5 of the 6 component criteria were present. If this was not attained, non-mastery was designated. Results revealed that the G \& T pupils had greater overall mastery of the 5 skills, however they did not master all skills. All G \& T had significantly increased jumping and throwing skills, and males significantly increased kicking skills. In both groups the majority of participation outside the school curriculum was related to games activities and was dominated by invasion games however no males participated in "aesthetic" activity outside school. These results indicate that development of FMS may not be occurring in children at KS3 and there is both an invasion games bias and a gender bias in the activities accessed out of school.
\end{abstract}

Keywords: FMS; Physical Literacy; G \& T; Year 9

\section{Introduction}

In the last two decades the recognition and investigation of Fundamental Movement skills (FMS) has developed and increased. It had been assumed that the development of these skills was a natural part of maturation however it is actually a more complex interactive process relating to biological constraints and the environment (Clarke, 2007). Happening virtually in tandem with this developing issue, the identification and discussion of giftedness within education was a relatively "new" concept which first arose in USA, DoE (1993) and in NSW, Australia, Department of Education and Training (DET) (1991). Following this in the UK, the "Excellence in cities" scheme (EiC) (DfEE, 2000) sought, in one strand, to promote and resource education for very able pupils, otherwise known as the "Gifted and Talented" (Bailey, Tan, \& Morley, 2006). This occurred at a time when the National Curriculum for Physical Education (NCPE) (2000), promoted inclusion as a key objective, and unlike the 1992 and 1995 curriculum moved from a "product" to a more "process" focus. So schools' role of supporting elite athlete development has been continually outlined by either the NCPE (1992) (DES/WO, 1992) or various policies, such as “A Sporting Future for All” (DCMS, 2000), Game Plan (DCSM/Strategy Unit 2002), the National Strategy for Physical Education, School Sport and Club Links
(PESSCYL) (DfES/DCMS, 2003), the PE and Sport Strategy for Young People (PESSYP) (DCSF/DCMS, 2008) and to a lesser extent the Talented Athlete Scholarship Scheme (TASS) (DCMS 2004).

So whilst NCPE (2000) clearly aimed to be inclusive other policies and initiatives sought to support and develop elite athletes within the PE arena. Croston (2012: 61) points out "merging the aims of PE and sport in policy added to the discursive... about what is actually educationally worthwhile practice in PE" and criticism highlights the shift towards "elite development, competition, and school sport". This, alongside the somewhat conflicting rhetoric of "inclusion" and "talent id" could be seen to place physical educationalists in a confusing predicament. This is perhaps likely to be further compounded by the recent National Curriculum in England framework document for consultation (DoE, 2013) with one stated aim to ensure all pupils "develop competence to excel in a broad range of physical activities” (DoE, 2013: 179). Previously the DCSF (2007) stated talented students were encompassed by the ability to excel in sport and artistic performance, which seems very similar to the more recent statement (DoE, 2013) outlined, which relates to all pupils and not talented pupils alone. Clearly the statements and aspirations conflict and it is perhaps questionable whether all pupils can be competent enough to excel in 
a range of activities. Regardless, this competence is based on gross motor development which has been "overlooked" in early education due to misconceptions that this naturally occurs (Clarke, 2007).

To facilitate competence pupils need to develop certain movement patterns, the key being breadth and balance of experience and a range of activity settings. Whitehead (2010: 3) continues, "there is a great deal of empirical research, for example, in cognitive science, that supports the fundamental importance of movement development”. PE in school is the main place where young people are assured of having experiences for physical skill development (Bailey, 2006; Whitehead, 2013), it is the place where PE teachers have the unique position of all pupils available (Williams, 2008). It represents perhaps the one opportunity for every young person to develop their motivation, confidence and competence in a balanced and breadth activities. Individuals who perform a broad range of movement competencies within their own physical capacity, applying these differently and understanding how they can develop further, encompass the term physical literacy (Whitehead, 2001). This literacy is built on blocks of movement termed Fundamental Movement Skills (FMS) which begin to develop in early childhood years (Stodden, Goodway, Langendorfer, Roberton, Rudisill, Garcia, \& Garcia, 2008) and are generally categorised into three different areas: locomotor, object control and manipulative skills. However Croston (2012) points out that talent identification in PE may undermine the participatory teaching practices which work toward developing the physically literate individuals (Whitehead, 2001) outlined previously. However this integration has perhaps been longstanding and is not aided by the often competitive bias of extra-curricular activities (Kirk, 2013).

There is a growing body of evidence (van Beurden, Zask, Barnett, \& Dietrich, 2002; Stratton, McWhannell, Foweather, Henaghan, Graves, Ridgers, \& Hepples, 2009; Lemos, Avigo, \& Barela; 2012; Stodden et al., 2008) that many children are delayed, or do not obtain proficiency in FMS development. This contrasts previous opinion, supporting the notion that children do not naturally learn FMS (Clarke, 2007) and it has to be nurtured. Development of these competences is a primary underlying mechanism that promotes engagement in physical activity whilst reduced development of motor competence corresponds to lower perceived motor skill competence and less physical activity (Stodden et al., 2008; Breslin, Murphy, McKee, Delaney, \& Dempster, 2012). Supporting these findings Okely and Booth (2004) found that the prevalence of mastery and near mastery in primary school children (aged 7.3 yrs) was low, with boys performing better in object control tasks and girls better in skipping. Using a similar method in children aged 9 - 10 yrs, Stratton et al. (2009) found that boys prevalence of mastery did not exceed $60 \%$ and in girls only the hop exceeded $30 \%$. This highlights a real concern as the expected age for mastery of FMS is 8/9 yrs (Gallahue \& Cleland, 2007). Whilst there are clear concerns about the overall FMS of our children, it might be expected that within the UK, given the support received through the PESSCYL strategy, at least those identified within schools as Gifted and Talented (G \& T) individuals and those who participate outside school PE lessons would have developed to mastery level. Given previous findings at KS2 it would be interesting to quantify FMS at KS3 and compare the abilities to $G$ and $T$ pupils. The aims of the study are to 1 ) quantify and compare the FMS skills of a Year 9 cohort and a
Year 9 G \& T cohort and 2) consider the influence participation out of the school curriculum having on these skills.

\section{Methods}

\section{Participants}

Twenty six G \& $T$ pupils participating in a Junior Athlete Education (JAE) day and nineteen pupils from a local secondary school volunteered to take part in the study. Their ages ranged from 13 - 14 yrs, girls $(n=23)$ and boys $(n=22)$. Consent was gained from the Head teacher/G and $\mathrm{T}$ co-ordinator and the right to withdraw at any time was re-iterated at the beginning of filming. The study was approved by Edge Hill University Ethics Committee.

\section{Assessment of Fundamental Movement Skills}

Each skill was assessed against 6 components considered essential to mastery of the skill. The skills were assessed using a process orientated measure focused on how the skill is performed (Knudson \& Morrison, 2002). Each skill was broken in to 6 components which afforded measurement a level of objectivity beyond that of a single score (van Beurden et al., 2002). Assessment was by video analysis of the specific criteria using a checklist derived from an existing assessment tool (Department of Education and Training, NSW, 2000) and with established validity and reliability (Okely \& Booth, 2000). The assessment tool enabled direct comparison to previous research. (Foweather, McWhanell, Henaghan, Lees, \& Stratton, 2008; Beurden et al., 2002).

The five skills that were assessed were vertical jump, hop, throw, kick and balance. The skills were considered due to their relative simplicity and variety. Recordings of each skill were taken from identical angles, with optimised image size and with separate cameras set up for the right/left handed throws and kicks. Data was taken from SD card converted to DVD for analysis. One trained assessor conducted all fundamental movement skill assessments. Groups were tested on separate days which limited any interaction. Children were given a verbal instruction and a single demonstration of each skill before they completed five trials. Children were grouped $(n=5)$ and moved between stations where the specific skills were filmed. Each subject rested whilst the group undertook their trial giving each participant a similar rest period between each trial. Additionally the children were given a questionnaire which was used to understand the amount and type of activity they regularly participated in outside of the school.

\section{Data Analysis}

Each skill was rated either $0=$ non-mastery or $1=$ mastery. Mastery/near Mastery was deemed to be 5 out of the six criteria being successfully demonstrated, whilst failure was deemed as demonstrating 4 or less. Frequency statistics were used to calculate overall, skill and criteria mastery from which group comparisons were analysed. Statistics, chi $^{2}$ with continuity correction was used.

\section{Results}

\section{Mastery Levels}

Figures 1 and 2 show the mastery levels of both groups in 
each of the five skills. Mastery levels are separated by gender showing mastery and non-mastery.

\section{Participation in Activities}

Table 1 reveals the participation rates of the pupils outside their classroom experience. This has been further categorized into the type of activity. Where a pupil engages in more than one activity area they have been included in both/all of the areas. The table shows that within both groups invasion games was the area in which the majority participated out of school. It also highlighted that only female participated in aesthetic activities out of school.

In both groups invasion games are the predominant activities participated in outside the curriculum. Aesthetic activities

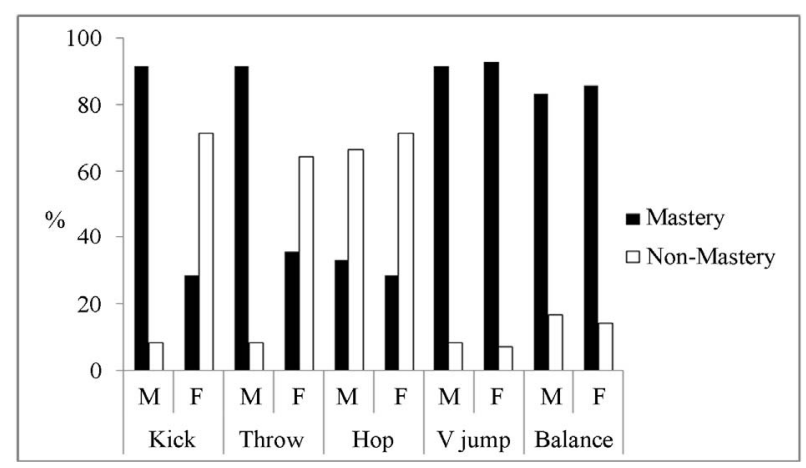

Figure 1.

Mastery and non-mastery of G \& T males and females.

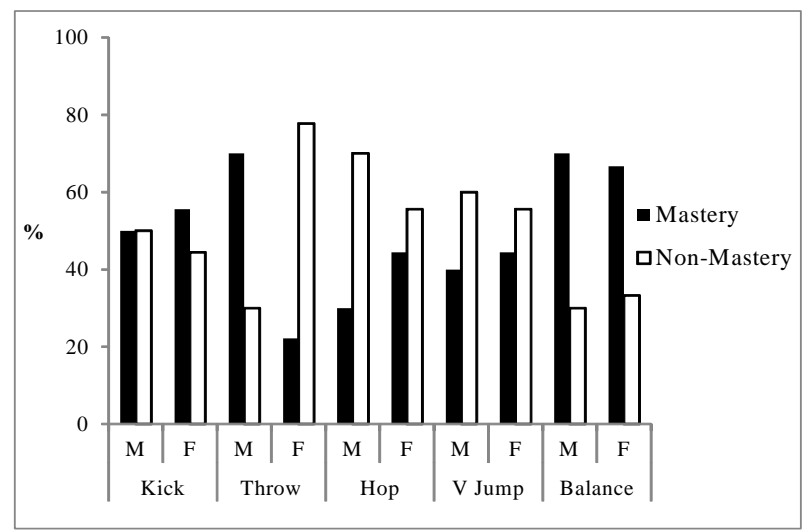

Figure 2.

Mastery and non-mastery of males and females in $\operatorname{Yr} 9$.

Table 1.

Involvement in extra-curricular activities.

\begin{tabular}{ccccccc}
\hline Activity & \multicolumn{3}{c}{ Boys } & \multicolumn{3}{c}{ Girls } \\
\hline & Total & Year 9 & G \& T & Total & Year 9 & G \& T \\
\hline Invasion & 21 & 9 & 12 & 15 & 6 & 9 \\
S \& F & 2 & 2 & 0 & 1 & 0 & 1 \\
N \& W & 6 & 6 & 0 & 3 & 1 & 2 \\
Aesthetic & 0 & 0 & 0 & 9 & 3 & 6 \\
Athletics & 1 & 0 & 1 & 5 & 4 & 1 \\
Other & 2 & 1 & 1 & 0 & 0 & 0 \\
\hline
\end{tabular}

(dance, gym and cheerleading) are only experienced by the females.

\section{Group Comparison}

Significant differences between the $\mathrm{G} \& \mathrm{~T}$ group and Year 9 cohort occur in both the Throw $\left(\chi^{2}=4.148, p<0.05\right)$ and the $\mathrm{V}$. Jump $\left(\chi^{2}=11.135, p<0.001\right)$.

\section{Gender Comparison}

Significant differences between males and females occur in the kick $\left(\chi^{2}=3.870, p<0.05\right)$. Whilst not significant, near significant differences $\left(\chi^{2}=3.736, p=0.053\right)$ occur in throwing highlighting gender differences in object control skills.

\section{Discussion}

It is expected that the majority of FMS should be achieved by the age of seven years (Clarke, 2007). However in this study, which only looked at 5 FMS, mastery of the skills is only achieved by $67 \%$ (males) and $21 \%$ (female) of $\mathrm{G} \& \mathrm{~T}$ pupils and $10 \%$ (male), $22 \%$ (female) of Yr 9 pupils. As the skills viewed were a mixture of object control, balance and locomotor skills it was apparent that at the age of 13 - 14 yrs young people may lack a range of movement skills and within both of the groups observed, do not achieve mastery in all of these basic skills. This finding reflects those of previous studies looking at younger children (van Buerden et al., 2002; Stratton et al., 2009). The results show that, whilst the groups differ in their FMS proficiency levels the G \& T have a 27\% increased overall mastery, however not all the $\mathrm{G} \& \mathrm{~T}$ pupils were proficient at the five FMS skills tested. Whilst this might be explained within specific object control skills, it is perhaps not expected in basic locomotor skills e.g. hopping which has at best $40 \%$ mastery in both groups. This poor mastery might suggest experience of hopping is limited both within and outside of school perhaps being viewed as of limited pedagogical importance. However care must be taken when interpreting this result as Barnett, van Beurden, Morgan, Lincoln, Zask and Beard (2009) found this test to be the least reliable of all the tests. However it is clear that mastery of hopping is relatively poor.

The occurrence of significant FMS differences and the achievement of some high levels of mastery are anomalous. Both groups have a similar mastery of the football kick (G \& T 60\%, Yr 9 53\%) an object control skill. Table 2 shows that whilst $92 \%$ of G \& T have mastered the vertical jump, which could be

Table 2.

Group comparison: FMS differences between the G \& T and Yr 9 groups.

\begin{tabular}{ccc}
\hline \multirow{2}{*}{ Skill } & \multicolumn{2}{c}{ Differences between G \& T and Yr 9 } \\
\cline { 2 - 3 } & Chi $^{2}$ & Significance \\
\hline Kick & 0.001 & 0.915 \\
Throw & 4.148 & $0.042^{*}$ \\
V. Jump & 11.135 & $0.001^{* *}$ \\
Balance & 0.861 & 0.654 \\
Hop & 0.011 & 0.915 \\
\hline
\end{tabular}

Note: ${ }^{*} p<0.05,{ }^{* *} p<0.01$. 
termed a relatively basic, perhaps non-specific skill, significantly, 58\% of Yr 9 have not. This kicking ability reflects the overall high participation rate in invasion games and more specifically football (50\%), which in turn is influenced by the cultural values of society (Gallahue \& Ozman, 2006). The significant group differences in jumping mastery, as seen in Table 2, seem to indicate a lack of this activity, related activity or specific skill activity within the curriculum. In contrast to kicking, reduced Yr 9 jumping mastery was observed even when out of school activities that require some basic jumping (netball/basketball) were well represented, indicating that "related" sport participation may not influence FMS. Additionally, there is decreased throwing mastery (compared to jumping) and a significant difference between groups, which is perhaps accounted for by this being an object control skill (Stratton et al., 2009; Booth, Okely, McLellan, Phongsavan, Macaskill, Patterson, Wright, \& Holland, 1999). This explanation should reflect a difference in the activities the groups experienced out of school however it does not, with the Yr 9 participating in more "throwing related activities". However the FMS test for kicking reflects the sport specific skill more closely than the throwing and jumping tests which may influence results. Looking at both throwing and jumping it could be argued that, 1) sport specific development does not assist (even detracts from) the development of certain FMS, 2) that the sport specific skills required may not be similar to the FMS tested or, 3 ) perhaps both. The lack of hopping mastery in both groups suggests it is neither encountered in the school curriculum by the groups nor experienced within the activities engaged in outside of school hours.

Within kicking, Table 3 highlights females significantly reduced kicking mastery and within throwing reduced mastery, $34 \%$ compared to $64 \%$ in males. Whilst not significant this is a clear gender difference in throwing ability reflecting the findings of Stratton et al. (2009). These gender and object control differences reflect the findings of Booth et al. (2006) and Barnett, van Beurden, Morgan, Brooks and Beard (2000). Significant gender differences do not occur in the hop, vertical jump and balance.

Expected timing of FMS mastery differs between skills but there are expected ages between 5 to 9 years by which specific skill criteria should be mastered (DoE, 1996). In specific skills certain criteria proved more difficult to master. Within object control skills in kicking particularly G \& T girls, struggled to "forward and sideward swing of arm opposite swing leg" and "Hip extension and knee flexion of at least 90 degrees during preliminary kicking movement”. In throwing "arm nearly

Table 3.

Gender comparison: FMS differences between males and females.

\begin{tabular}{ccc}
\hline \multirow{2}{*}{ Skill } & \multicolumn{2}{c}{ Differences between male and females } \\
\cline { 2 - 3 } & Chi $^{2}$ & Significance \\
\hline Kick & 3.870 & $0.049^{*}$ \\
Throw & 3.736 & 0.053 \\
V. Jump & 0.009 & 0.924 \\
Balance & 0.000 & 1.000 \\
Hop & 0.000 & 1.000
\end{tabular}

Note: ${ }^{*} p<0.05,{ }^{* *} p<0.01$. straightened behind the body" and "marked sequential hip to shoulder rotation during the throw" were poorly mastered. In the vertical jump between 55\% - 60\% could not "crouch with knees bent and arms behind the body" and "forceful upward thrust of arms as legs straighten to take off”. In hopping, "takes off and lands on forefoot" and "able to hop on both right and left legs". This reflects the findings of Scott, Williams and Horn (2003) that use of the open kinetic chain occurred as technique became more mature. All being mastered later reflecting the model of expected criteria mastery (DoE, 1996). So whilst some of the basic criteria are mastered, more complex, co-ordinated criteria are not.

As the expectation is that this occurs before KS3 this implies that at a crucial developmental time children are not experiencing, certainly not in any depth, activities which would encourage this development (Hardy, King, Farrell, Maciver, \& Howlett, 2010). Given the influence of perceived competence on participation and achievement it is also perhaps unlikely then that a policy promoting competition is going to be more successful if basic skills are not being achieved. The lack of FMS mastery is likely to have an effect on the development of physical literacy, participation throughout life and long term athlete development (LTAD). At a time when health, competition and achievement are high on Government agendas, reduced FMS development and its' long term influence on motivation and participation needs to be addressed if physical education targets are to be achieved. Interestingly Koshy, Pinheiro-Torres and Portman-Smith (2010) found the topic of younger children was mainly ignored when auditing conferences and courses on G \& T education between 2007 and 2009, nor could they find training courses to support teachers of the younger age group. This would clearly disadvantage instruction of the younger age group at a time when many are arguing for more specialist input. Kirk (2005: 2013) has argued that PE specialism teachers should preferably be based at primary level, when pupils are initially receptive to motor skill development (Clark, 2007). Strengthening this argument Lemos, Avigo and Barela (2012: 20) found "at the end of a school year, children enrolled in physical education activities, provided by specialists, showed better performance than children enrolled in recreational activities". Whilst the new NCPE guidelines highlight competition as important and primary school PE/sport investment is to be re-introduced, it is questionable, considering the past investment and the findings outlined, whether this alone is the answer. As Lemos et al. (2012) found and Hardy et al. (2010) concluded that provision by specialist teachers at primary/kindergarten level providing regular physical activity would promote better development of gross motor skills.

\section{Conclusion}

This research highlights that skill development is not as "rounded" as it could be for pupils and even with identification and investment of our "talented" pupils; skill development may be specific activity. Many children are not achieving the levels of expectations particularly the more complex FMS criteria perhaps, in part, due to a lack of balance and depth in fundamental movement skills within our schools but also possibly as a result of specific sport practice within clubs at a young age. Mastery in some skills, particularly object control skills, may benefit and be influenced by sport specialization at young age. However this specialization may detract from FMS develop- 
ment and, in the long term, may limit overall physical development for life compromising both the ability to excel across activities and overall sporting excellence. Even with overt inclusion policies and $\mathrm{G} \& \mathrm{~T}$ policies being prevalent within schools and PE, it appears that those skills which are suggested as the building bricks for movement, and therefore in part physical literacy, are not being fully developed in our children. It is perhaps time to look carefully at the construction and instruction of the "physical" provision in our primary schools to ensure these building blocks are developed.

\section{REFERENCES}

Bailey, R., Tan, J. E. C., \& Morley, D. (2004). Talented pupils in physical education: A national survey of policy and practice in England. Physical Education and Sport Pedagogy, 14, 59-72. http://dx.doi.org/10.1080/17408980701712007

Bailey, R. (2006). Physical Education and Sport in Schools: A review of benefits and outcomes. Journal of School Health, 76, 397-401. http://dx.doi.org/10.1111/j.1746-1561.2006.00132.x

Barnett, L., van Beurden, E., Morgan, P. J., Lyndon, O., \& Beard, J. R. (2010). Gender differences in motor skill proficiency from childhood to adolescence. Research Quarterly for Exercise and Sport, 81, 162-170.

Barnett, L., van Beurden, E., Morgan, P. J., Lincoln, D., Zask, A., \& Beard, J. (2009). Interrater objectivity for field-based fundamental motor skill assessment. Research Quarterly for Exercise and Sport, 80, 363-368. http://dx.doi.org/10.1080/02701367.2009.10599571

Booth, M. L., Okely, T., McLellan, L., Phongsavan, P., Macaskill, P., Patterson, J., Wright, J., \& Holland, B. (1999). Mastery of fundamental motor skills among New south wales school students: Prevalence and sociodemographic distribution. Journal of Science and Medicine in Sport, 2, 93-105.

http://dx.doi.org/10.1016/S1440-2440(99)80189-3

Booth, M., Okely, A. D., Denney-Wilson, E., Hardy, L., Yang, B., \& Dobbins, T. (2006). NSW schools physical activity and nutrition survey (SPANS). Sydney, Australia: NSW Department of Health.

Breslin, G., Murphy, M., McKee, D., Delaney, B., \& Dempster (2012). The effects of teachers trained in a fundamental movement skills programme on children's self-perceptions and motor competence. European Physical Education Review, 18, 114-126. http://dx.doi.org/10.1177/1356336X11430657

Clarke, J. E. (2007). On the problem of motor skill development. Journal of Physical Education, Recreation and Dance, 78, 39-44. http://dx.doi.org/10.1080/07303084.2007.10598023

Croston, A. (2012). "A clear and obvious ability to perform physical activity”: Revisiting physical education teachers' perceptions of talent in PE and sport. Physical Education and Sport Pedagogy, 18, 60-74. http://dx.doi.org/10.1080/17408989.2011.631001

DCMS (2000). A sporting future for all. London, UK: Department for Culture, Media \& Sport.

DCMS (2004). The talented athlete scholarship scheme. London, UK: Department for Culture, Media \& Sport.

DCMS \& Sport/Strategy Unit (2002). Game plan: A strategy for delivering government's sport and physical activity objectives. London, UK: Department for Culture, Media \& Sport/Strategy Unit.

DCSF (2007). Effective provision for gifted and talented students in secondary education. London, UK: Department for Children, Schools and Families.

DCSF/DCMS (2008). The Physical Education and school sport strategy for young people. London, UK: Department for Children, Schools and Families/Department for Culture, Media and Sport.

DES/WO (1992). Physical education in the national curriculum. London, UK: Department of Education and Science/Welsh Office.

DET (1992). Policy and implementation strategies for the education of gifted and talented students. State of NSW, Australia: Department of Education and Training, Curriculum K-12.

DET (2000). Get skilled: Get active. A K-6 resource to support the teaching of fundamental movement skills State of NSW. Australia:
Department of Education and Training.

DfEE (2000) Excellence in Cities; Report March 1999-September 2000. London, UK: Department for Education and Employment.

DfES/DCMS (2003). The national strategy for physical education, school sport and club links (PESSCL). Learning through PE and sport. London, UK: Department for Education and Skills/Department for Culture, Media and Sport.

DoE (1993). National Excellence: A case for developing America's Talent. Washington, DC: Office of Educational Research and Improvement.

DoE (1996). Fundamental Motor Skills: A Manual for Classroom Teachers. Melbourne, Victoria: Department of Education.

DoE (2013). Physical Education: Programmes of study for Key Stages 1-4. A consultation document. London, UK: Department for Education.

Foweather, L., McWhannell, N., Henaghan, J., Lees, A., Stratton, G., \& Batterham, A. (2008) Effect of a 9-wk. after-school multiskill's club on fundamental movement skill proficiency in 8 to 9 yr old children: an exploratory trial. Perceptual \& Motor Skills, 106, 745-754. http://dx.doi.org/10.2466/pms.106.3.745-754

Gallahue, D., \& Cleland-Donnelly, F. (2007). Developmental physical education for all children (4th ed). Champaign, IL: Human Kinetics.

Gallahue, D. L., \& Ozmun, J. C. (2006). Understanding Motor Development: Infants, Children, Adolescents, Adults ( $6^{\text {th }}$ ed). New York: McGraw-Hill.

Hardy, L. A., Kingl, Farrell, L., Macniven, R., \& Howlett, S. (2010). Fundamental movement skills among australian preschool children. Journal of Science and Medicine in Sport, 13, 503-508. http://dx.doi.org/10.1016/j.jsams.2009.05.010

Kirk, D. (2005). Physical education, youth sport and lifelong participation: the importance of early learning experience. European Physical Education Review, 11, 239. http://dx.doi.org/10.1177/1356336X05056649

Kirk, D. (2013). What is the future for physical education in the twentyfirst century? In S. Capel, \& M. Whitehead (Eds.), Debates in physical education (pp. 220-231). Abingdon, Oxford: Routledge.

Koshy, V., Pinheiro-Torres, C., \& Portman-Smith, C. (2010). The landscape of gifted and talented education in england and wales: How are teachers implementing policy? Research Papers in Education, 27, 167-186. http://dx.doi.org/10.1080/02671522.2010.509514

Knudson, V., \& Morrison, S. (2002). Qualitative analysis of human movement. Champaign, IL: Human Kinetics.

Lemos, G. A., Avigo, E. L., \& Barela, J. A. (2012) Physical education in kindergarten promotes fundamental movement skills. Advances in Physical Education, 2, 17-21. http://dx.doi.org/10.4236/ape.2012.21003

Okley, A. D., \& Booth, M. L. (2000). The development and validation of an instrument to assess children's fundamental movement skill ability. 2000 Pre-Olympic Congress Sports Medicine and Physical Education Internal Congress on Sport Science, Brisbane, Australia.

Okely, A. D., Booth, M. L., \& Patterson, J. W. (2001) Relationship of physical activity to fundamental movement skills among adolescents. Medicine and Science in Sports and Exercise, 33, 1899-1904. http://dx.doi.org/10.1097/00005768-200111000-00015

Okley, A. D., \& Booth, M. L. (2004). Mastery of fundamental movement skills among children in new south wales: prevalence and sociodemographic distribution. Journal of Science and Medicine in Sport, 7, 358-372. http://dx.doi.org/10.1016/S1440-2440(04)80031-8

Scott, M. A., Williams, M. A., \& Horn, R. R. (2003). The co-ordination of kicking techniques in children. In G. Savelsbergh, K. Davids, J. van der Kamp, \& S. J. Bennett (Eds.), Development of movement co-ordination in children:Applications in the Fields of Ergonomics, Health Sciences and Sport (pp. 241-250). London: Routledge.

Stodden, D. F., Goodway, J. D., Langendorfer, S. J., Roberton, M. A., Rudisill, M. E., Garcia, C., \& Garcia, L. E. (2008). A developmental perspective on the role of motor skill competence in physical activity: An emergent relationship. Quest, 60, 290-306. http://dx.doi.org/10.1080/00336297.2008.10483582

Stratton, G., McWhannell, N., Foweather, L., Henaghan, J., Graves, L., Ridgers, N. D., \& Hepples, J. (2009) The A-CLASS project research findings: Summary Report. Liverpoo, UK: Sportslinx. 


\section{G. GRIFFITHS, R. BILLARD}

van Beurden, E., Zask, A., Barnett, L., \& Dietrich, U. (2002) Fundamental movement skills-How do primary school children perform? The "Move it Groove it" program in rural Australia. Journal of Science \& Medicine in Sport, 53, 244-252.

http://dx.doi.org/10.1016/S1440-2440(02)80010-X

van Beurden, E., Barnett, L. M., Zask, A,. Dietrich, U. C., Brooks, L. O., \& Beard, J. (2003). Can we skill and activate children through primary school physical education lessons? Preventive Medicine, 36, 493-501. http://dx.doi.org/10.1016/S0091-7435(02)00044-0

Whitehead, M. E. (2001). The concept of physical literacy. European Journal of Physical Education, 2, 127-138.
Whitehead, M. E. (2010). Physical literacy: Throughout the lifecourse. Abingdon. Oxford: Routledge.

Whitehead, M. E. (2013). What is physical literacy and how does it impact on physical education? In S. Capel, \& M. Whitehead (Eds.), Debates in Physical Education (pp. 37-52). Abingdon, Oxford: Routledge.

Williams, G. (2008). Gifted and talented in physical education... or is it sport? Physical Education Matters, 3, 19-22. 